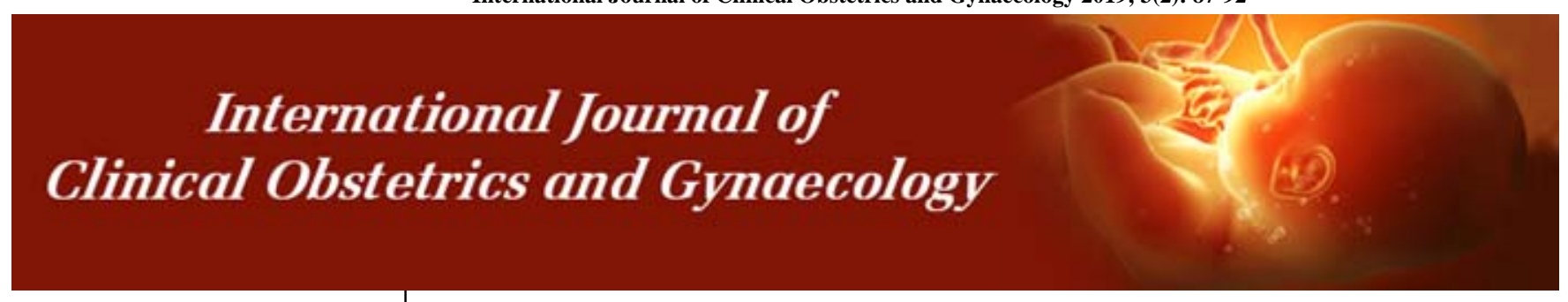

ISSN (P): 2522-6614

ISSN (E): 2522-6622

(C) Gynaecology Journal

www.gynaecologyjournal.com

2019; 3(2): 87-92

Received: 15-01-2019

Accepted: 19-02-2019

Dr. Madhumita

Postgraduate, Obstetrics and

Gynaecology, Sri Ramachandra

Institute of Higher Education and

Research, Tamil Nadu, India.

Dr. Rajeswari

Professor, Obstetrics and

Gynaecology, Sri Ramachandra

Institute of Higher Education and

Research, Tamil Nadu, India.

Dr. Preet Agarwal

Associate professor, Obstetrics and

Gynaecology, Sri Ramachandra

Institute of Higher Education and

Research, Tamil Nadu, India.
Correspondence

Dr. Madhumita

Postgraduate, Obstetrics and

Gynaecology, Sri Ramachandra

Institute of Higher Education and

Research, Tamil Nadu, India.

\section{A rare case series on cervical pregnancy}

\author{
Dr. Madhumita, Dr. Rajeswari and Dr. Preet Agarwal \\ DOI: https://doi.org/10.33545/gynae.2019.v3.i2b.17
}

\section{Abstract}

Introduction: Cervical ectopic pregnancy is a rare life threatening condition that implants in the endocervical lining, accounting for less than $1 \%$ of all ectopics.

Aim: Successful diagnosis, management and challenges of cervical pregnancy.

Study Design: A case series on 5 cases of cervical pregnancy in SRMC, Chennai, their timely diagnosis, associated risk factors (previous surgeries, ART) and management modalities - foleys tamponade, Multi dose methotrexate regimen, suction and evaluation with or without UAE.

Results: The mean gestational age of diagnosis was seven weeks. The median serum human chorionic gonadotropin level was 11300 IU/L (range 610 to 163 700). Fetal cardiac activity was present in 1 case. Vaginal bleeding was the most common presentation.

All cases were successfully managed conservatively, thus allowing uterine preservation. Systemic methotrexate (multi-dose protocol) was the mainstay of therapy. Other minimally invasive interventions included ultrasound-guided injection of potassium chloride into the pregnancy, uterine artery embolization, and dilatation and curettage, with Foley catheter tamponade.

Conclusion: Cervical pregnancy has become not so rare now with risk factors like high caesarian rate and ART. Hence, timely diagnosis by ultrasound and effective management reduces the risk of severe life threatening hemorrhage or hysterectomy.

Keywords: Cervical ectopic, Bhcg, Transvaginal ultrasound, hourglass appearance, methotrexate, suction and evacuation

\section{Introduction}

Cervical ectopic pregnancy is a rare life threatening condition that implants in the endocervical lining, accounting for less than $1 \%$ of all ectopics

- Incidence - 1 in 8600 pregnancies, now increasing due to increasing ART $(0.1 \%$ of IVF pregnacies and $3.7 \%$ of IVF ectopic pregnancies.) and previous surgeries.

- Sonographic criteria for diagnosis of cervical pregnancy

- gestational sac or placenta within the cervix

- normal endometrial stripe

- (hourglass/ figure of eight) shaped uterus with ballooned cervical canal

- Other signs include visualization of an embryo or fetus in the intracervical area and gestational sac below the level of the internal cervical os or uterine arteries.

\section{Objective}

- Successful and timely management and challenges in diagnosis of cervical pregnancy.

\section{Materials and Methods}

An observational study of 5 cases of Cervical pregnancy, conducted in Sri Ramachandra University, Chennai, from December 2017 to December 2018. It includes a Detailed history, Clinical Examination, Ultrasound evaluation and serial monitoring of serum Bhcg levels and its various medical (Single /multiple dose Methotrexate regimen, Foleys tamponade, Intra amniotic KCL injection) and surgical (Suction and Evacuation with / without UAE) management and its outcome.

Case 1

- $\quad$ Primigravida at 5 weeks +5 days came with complaints of painless spotting P/V for the past 7 days.

- $\quad$ Surgical history-Cervical polypectomy done 1yr back 
- Vitals stable

- $\quad \mathrm{P} / \mathrm{A}-\mathrm{Soft}, \mathrm{BS}+$, No tenderness

- $\mathrm{P} / \mathrm{S}-\mathrm{OS}$ closed

- $\mathrm{P} / \mathrm{V}-\mathrm{OS}$ closed, bleeding+, no forniceal tenderness, no cervical motion tenderness

- Baseline investigations:-

Hb-11.7g/dl, Beta HCG - $4292 \mathrm{mIU} / \mathrm{ml}$

Repeat Beta HCG -7072 mIU/ ml (48hrs later - outside)

- TVS - Thickened echogenic cavity with right adnexa showing Heterogenous mass of 2.1 x $1.8 \mathrm{~cm}$ with vascularity.

- $\quad$ Rpt Beta HCG -18, 271 mIU/ml (On admission)

Impression: Right Unruptured ectopic pregnancy. In view of increasing Sr Beta HCG patient planned for laproscopic salpingectomy.
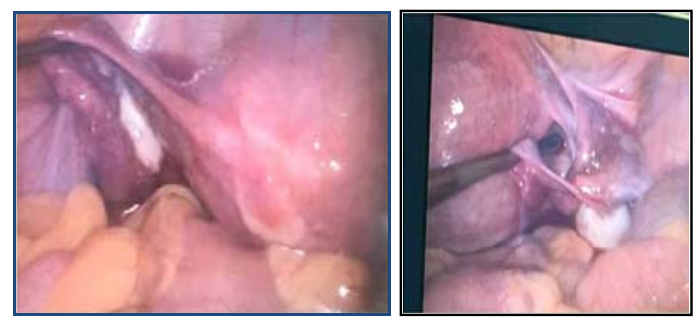

Intra - Operatively Bilateral Tubes and Ovaries Normal. Abdominal cavity examined thoroughly

\section{Pregnancy of Unknown Site}

Intra operatively TVS done - Sonologist called over.

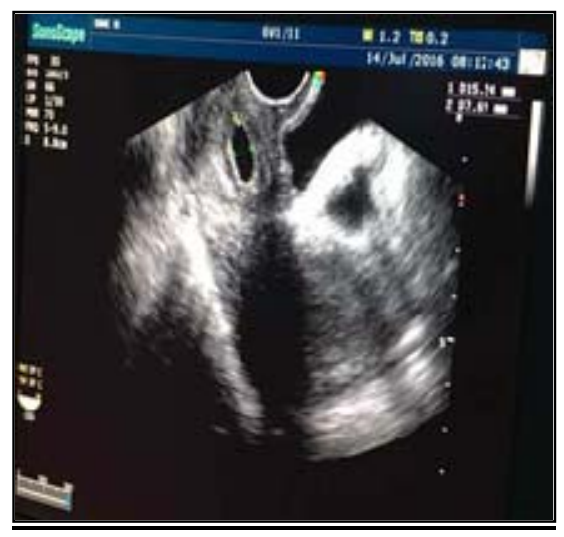

Hyperechoic Lesion of $2 x 2 \mathrm{~cm}$ noted in the cervical canal-? Gestational sac

\section{Diagnosis of Cervical Pregnancy confirmed.}
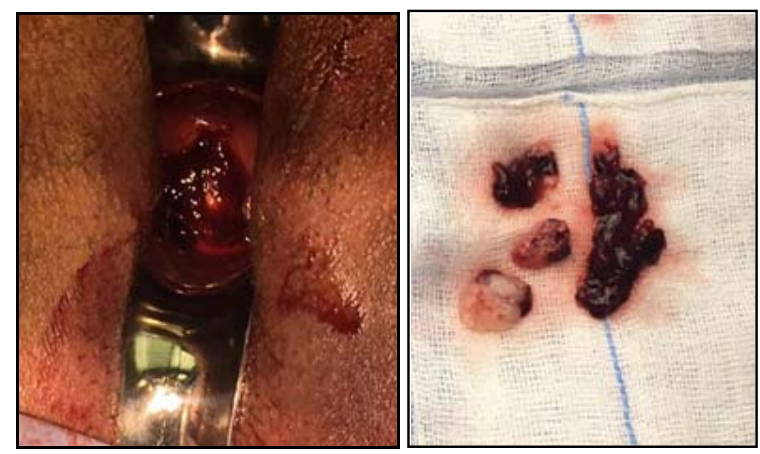

Attenders and interventional radiologist informed (for UAE if needed) Adequate blood products reserved. Products removed in toto under usg guidance after vasopressin injection. Suction and Evacuation Done

Foleys tamponade done. Products sent for HPE. No undue bleeding. Foleys removed after 24 hrs.

Follow up Bhcg -

POD 1 - $4614 \mathrm{mIU} / \mathrm{ml}$

POD 5 - $399.2 \mathrm{mIU} / \mathrm{ml}$

POD 12 - $22.2 \mathrm{mIU} / \mathrm{ml}$

POD $19-<2 \mathrm{mIU} / \mathrm{ml}$

HPE - products of gestation.

\section{Case 2}

- Primi @6w+5D / OI conception came with complaints of pain abdomen on and off with mild spotting $\mathrm{P} / \mathrm{V}$.

- $\quad \mathrm{O} / \mathrm{E}$ : vitals stable, P/A: mild tenderness in lower abdomen.

- L/E: No bleeding noted.

- $\mathrm{P} / \mathrm{V}$ : OS closed.

- On admission Bhcg - 21553mIu/ml.

- $\quad$ TVS done showed Single gestational sac just distal to cervix with minimal subchorionic hemorrhage with foetus of CRL$2.5 \mathrm{~mm}$ with $\mathrm{FH}$ seen

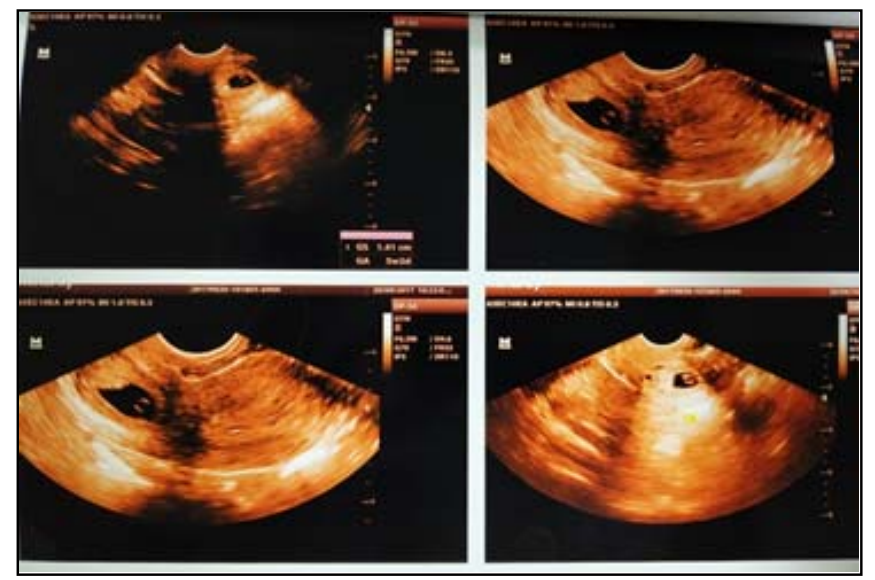

Fig D: Transvaginal USG of Cervical pregnancy - with an hourglass appearance of uterus, a closed internal os and a gestational sac containing live embryo in intracervical canal. 


\section{Suggestive of Cervical Pregnancy.}

- $\quad$ Patient started on multidose Inj Methotrexate regimen. Bhcg values on Day 2 - 30108, Day 4 - 30765. Intra amniotic
KCL injection given under USG guidance. Continued with $4^{\text {th }}$ dose Methotrexate regimen.

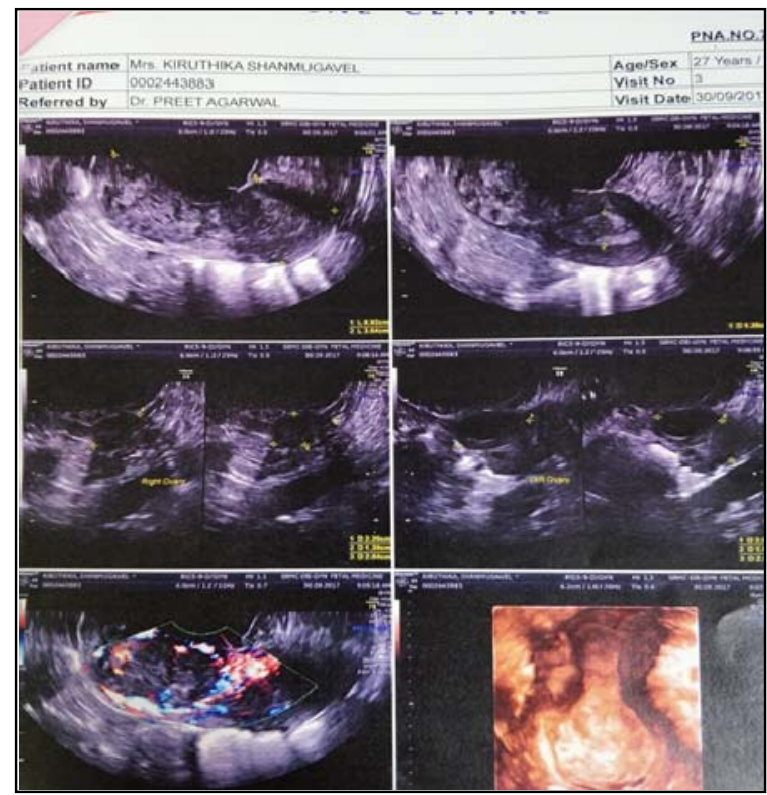

- Repeat scan done showed Endometrial Thickness - 14mm, cervical canal appears distended with echogenic debris of $3.8 * 3.5 \mathrm{~cm}$.

- $\quad$ Serial Bhcg - 20911(Day 7), 16284(Day 9), 10520 (Day 11). Follow up Bhcg values - 398.2 on D21 and finally Bhcg-3 on Day 30.

\section{Case 3}

- G2P1L1@6wks+6d/ Previous LSCS with medical abortion tried outside without any usg scan confirming pregnancy came with complaints of profuse bleeding $\mathrm{p} / \mathrm{v}$.

- O/E : PR -120/min, BP - 110/70mmHg P/A - soft,

- $\mathrm{P} / \mathrm{S}$ : 70gms clots removed from vagina

- $\mathrm{P} / \mathrm{V}$ : cervix ballooned out, soft, Ut bulky, Bleeding ++ (torrential)

- Immediate Bleeding controlled by Foleys tamponade.

- On admission - Hb - 6.1, TC- 20100, Bhcg - 8328mIu/ml. Anemia corrected with3 units PC and 4units FFP. TVS done in SRMC showed $1.7^{*} 1.3 \mathrm{~cm}$ mass of mixed echogenicity seen in the cervix. Started on Multidose Methotrexate regimen. Foleys removed after 48hrs.

- $\quad$ Follow up Bhcg values - 2575, 2211, 950,

\section{Case 4}

- Primi @7wks+3days came with complaints of bleeding p/v and severe pain abdomen.

- $\mathrm{P} / \mathrm{a}$ - soft, no tenderness,

- $\quad$ P/S: Cervix appears ballooned out, External Os closed.

- On admission Hb-5.6, Bhcg - 5574. Anemia corrected with 2unit PC. TVS pelvis showed Gestational sac in the lower part of uterus with foetal pole and absent FH

\section{Diagnosis: Inevitable abortion}

- 2 doses of T. Misoprostol 400mg P/V 4hrs interval given overnight but no further expulsion of poc seen. Rpt TVS in labour room showed Gestational sac seen in the same place and with the same contour.

\section{Suspicious of cervical pregnancy.}

Hence repeat scan confirmed the diagnosis of cervical pregnancy as she was bleeding bilateral Uterine Artery Embolisation was done with evacuation done - products removed in to.
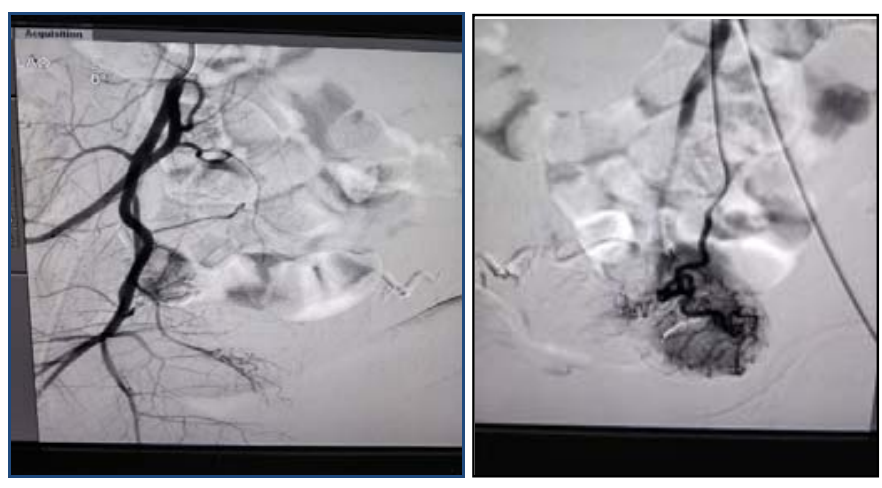


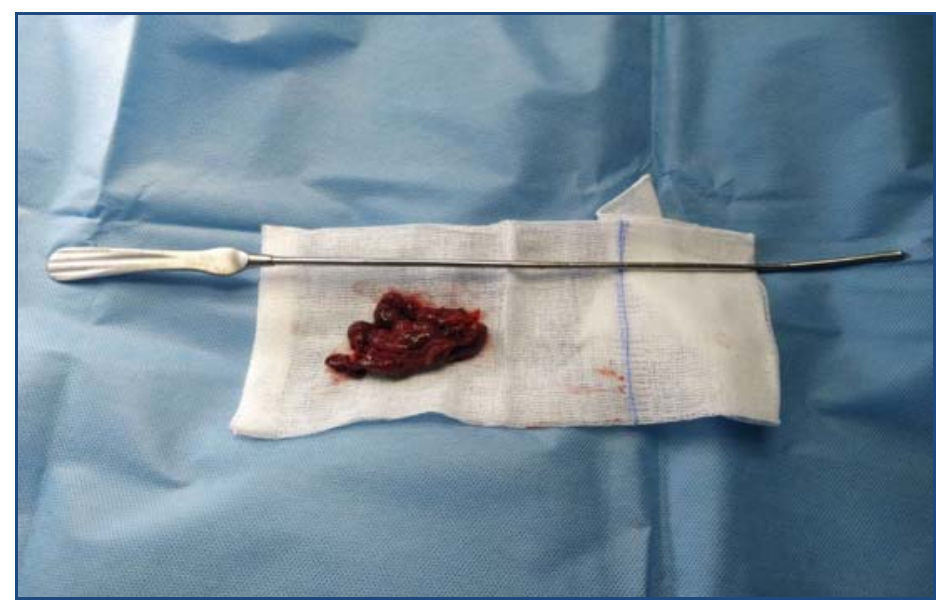

- $\quad$ Post op Bhcg - 904. Follow up Bhcg - 600, 299, 67, 42, 11. HPE showed products of gestation.

\section{Case 5}

- Primi at 7weeks gestation, spontaneous conception, came with h/o passage of clots. No previous surgeries. TVS done outside showed cervical pregnancy of 6wks gestation with CRL-3.9mm and FH seen. Hence patient referred to higher centre for management.

- On admission Hb- 12.3, TC- 8000, Bhcg -8111. Repeat TVS done showed gestational sac seen in the cervix with no fetal pole or yolk sac. Hence started on Multidose Methotrexate regimen. Follow up Bhcg - 604, 243 and 15 respectively.

\section{Results}

The mean gestational age of diagnosis was seven weeks. The median serum human chorionic gonadotropin level was 11300 IU/L (range 610 to 163 700). Fetal cardiac activity was present in 1 case. Vaginal bleeding was the most common presentation. All cases were successfully managed conservatively, thus allowing uterine preservation. Systemic methotrexate (multidose protocol) was the mainstay of therapy. Other minimally invasive interventions included ultrasound-guided injection of potassium chloride into the pregnancy, uterine artery embolization, and dilatation and curettage, with Foley catheter tamponade

\begin{tabular}{|c|c|c|c|c|c|}
\hline & Case A & Case B & Case C & Case D & Case E \\
\hline Parity & Primi & Primi & G2P1L1 & Primi & Primi \\
\hline Antecedents & Cervical polypectomy & OI conception & $\begin{array}{c}\text { Previous LSCS/OI } \\
\text { conception }\end{array}$ & nil & nil \\
\hline Bhcg & $\begin{array}{c}4292,7072,18271, \\
4614,399,22,4\end{array}$ & $\begin{array}{c}21553,30108,30765, \\
20911,10520,398,58,6\end{array}$ & $\begin{array}{c}\text { 8328, 2575, 2211, } \\
950,112,32 \\
\end{array}$ & $\begin{array}{c}5574,904, \\
600,299,67,42,11\end{array}$ & 8111, 604,243, 15. \\
\hline $\begin{array}{c}\text { Admission } \\
\text { investigations }\end{array}$ & $\mathrm{Hb}-11.4$ & Hb-11, TC - 13900 & $\begin{array}{c}\text { Hb- 6.1, TC - } \\
20100\end{array}$ & Hb- 5.4, TC - 7000 & Hb- 12.3,TC- 8000 \\
\hline USG & $\begin{array}{c}\text { 1. Thickened echogenic } \\
\text { cavity, } \\
\text { R adnexa }-2.1^{*} 1.8 \mathrm{~cm} \\
\text { mass } \\
\text { ?R unruptured ectopic } \\
\text { On table - Tubes and } \\
\text { ovariex normal. } 2 * 2 \mathrm{~cm} \\
\text { hyperechoeic lesion } \\
\text { noted in the cervix }\end{array}$ & $\begin{array}{l}\text { Single gestational sac } \\
\text { distal to cervix with } \\
\text { crl-2.5mm with FH+ }\end{array}$ & $\begin{array}{l}1.7 * 1.3 \mathrm{~cm} \text { mass of } \\
\text { mixed } \\
\text { echogenicity in the } \\
\text { cervix }\end{array}$ & $\begin{array}{c}\text { Gestational sac with } \\
\text { foetal pole and absent } \\
\text { FH } \\
\text { ?in the cervical canal }\end{array}$ & $\begin{array}{l}\text { Outside -Probable cervical } \\
\text { pregnancy of } 6 \text { wks } \\
\text { gestation with CRL-3.9mm } \\
\text { and FH seen. } \\
\text { After h/o passage of clots, } \\
\text { USG showed Gestational } \\
\text { sac seen in the cervix with } \\
\text { no fetal pole or yolk sac }\end{array}$ \\
\hline $\begin{array}{c}\text { Medical } \\
\text { management }\end{array}$ & & $\begin{array}{c}\text { Multi dose } \\
\text { methotrexate regimen }\end{array}$ & $\begin{array}{l}\text { Foleys tamponade. } \\
\text { Multi dose } \\
\text { Methotrexate } \\
\text { regimen }\end{array}$ & $\begin{array}{l}\text { Medical termination } \\
\text { with Misoprostol }\end{array}$ & $\begin{array}{l}\text { Multi dose Methotrexate } \\
\text { regimen. }\end{array}$ \\
\hline $\begin{array}{c}\text { Surgical } \\
\text { management }\end{array}$ & $\begin{array}{l}\text { Laparascopy and } \\
\text { Suction and evacuation } \\
\text { Foleys tamponade }\end{array}$ & $\begin{array}{c}\text { Intra amniotic KCL } \\
\text { injection }\end{array}$ & & $\begin{array}{l}\text { Uterine Artery } \\
\text { embolisation } \\
\text { Suction and } \\
\text { Evacuation }\end{array}$ & \\
\hline
\end{tabular}


The findings of the case series are illustrated in Table 1. All patients included in the study presented with complaints of bleeding or spotting per vaginum. 2 cases had history of previous surgery being LSCS and polypectomy with dilatation and curettage. There were 2 cases of conception by ovulation induction. 3 out of 5 cases were managed with multidose methotrexate regimen, out of which 2 were exclusively managed, while the other 1 required higher modality of management, being suction and evacuation with Foley's tamponade/ ultrasound guided intra-cardiac $\mathrm{KCl}$ injection. The $5^{\text {th }}$ case required uterine artery embolisation. Cases A and D were misleading initially. Case A was initially diagnosed to be tubal ectopic, managed with multidose methotrexate regimen. However, in view of increasing beta hCG trend, she was planned for laparoscopic salphingectomy. Intra-operatively, fallopian tubes were normal and there were no features of abdominal ectopic. Ultrasound imaging confirmed cervical pregnancy and hence, proceeded with suction and evacuation with foley's tamponade. (Fig 2, 3) Case D initially diagnosed as incomplete abortion, which did not respond to medical management. In view of suspicion of cervical pregnancy, ultrasound imaging was done to confirm the same. She subsequently underwent uterine artery embolisation with suction and evacuation. Conservative management was deferred for case $\mathrm{D}$ in view of moderate anemia with bleeding $\mathrm{P} / \mathrm{V}$. All cases were followed up with weekly beta hCG monitoring. Case B developed organized blood clots post-operatively which was managed conservatively with IV antibiotics and analgesics.

\section{Discussion}

Although non-tubal ectopic pregnancies do account for about only $5 \%$ of ectopic pregnancies, they are responsible for significant morbidity (Condous, 2002) and are potentially lifethreatening. Maternal mortality related to Cervical Pregnancy has dropped from $40-45 \%$ to $0-6 \%$ in the past 50 yrs (Wolcott, 1989)

The uterine cervix is predisposed for nidation because of its high vascularization. At the same time, this high grade of vascularization renders this site especially vulnerable to lifethreatening uncontrollable bleeding. Another factor that contributes to the increased risk of severe bleeding in cervical pregnancy is the microscopic architecture and the function of the cervical part of the uterus. Only $20 \%$ of the cervix consists of smooth muscle, the fibrous tissue is not contractile and insusceptible to mechanical hemostatic manipulation and uterotonic agents. Therefore, in the past, cervical ectopic pregnancy was traditionally treated by hysterectomy, with cervical pregnancy only diagnosed retrospectively by histopathological examination.

There are three options for the management of an ectopic pregnacy in general: expectant - which is reserved to early ectopic pregnancies with low and declining serum hCG levels medical or surgical. In fact, spontaneous resolution has been reported in up to $69 \%$ of cases. ${ }^{[7]}$ However, the risk of spontaneous hemorrhage in these cases is very high as ectopics account for $9 \%$ of all maternal deaths due to severe bleeding. Apply expectant management only if the initial hCG level is under $2000 \mathrm{mIU} / \mathrm{ml}$ and decreases in the proceeding serum controls.

Treatment options to preserve the uterus in the case of cervical pregnancy consist of tamponade, reduction of blood supply, excision of trophoblastic tissue, intra-amniotic fetocide and systemic chemotherapy. ${ }^{[6]}$ In most cases, successful conservative therapy consists of a combination of these methods.
Alternatives for the treatment of cervical ectopics consist of three major principles:

- mechanical termination of the EP by curettage,

- $\quad$ systemic or local application of MTX,

- hemostasis.

Which can be achieved by different means: local injection of vasopressin and cerclage, ${ }^{[6]}$ cervical-stay sutures, tamponade by a Foley balloon or ligation, or embolization of the descending branches of the uterine arteries. ${ }^{[8]}$

As cervical pregnancies are well vascularized, surgery might be associated with severe hemorrhage. Women with uncontrolled bleeding might need blood transfusions, postoperative intensivecare-unit treatment or even a hysterectomy. ${ }^{[7]}$ Therefore, Agdi et al. recommend an intravenous line with a large-bore needle, four units of blood for possible transfusion, and a Foley catheter for accurate monitoring of intake and output. In women who wish to preserve their fertility and to avoid hysterectomy, insertion of an angiographic catheter to the uterine arteries could be necessary in order to perform an arterial embolization in the presence of uncontrolled bleeding. ${ }^{[7]}$

Jeng et al, ${ }^{[3]}$ likewise, terminated 38 cervical ectopic pregnancies with ultrasound-guided methotrexate injection, with a mean time to resolution of 49 days. Uterine artery embolization alone, or followed by curettage, has terminated cervical pregnancies without significant hemorrhage, preserving the uterus. ${ }^{[12,13]}$ Parente et al ${ }^{[14]}$ reported 5 cases in 1983, 4 of which required hysterectomy, and the fifth was successfully treated with curettage and vaginal packing. Vela and Tulandi ${ }^{\text {[5] }}$ reported in 2007, 12 cases treated over 20 years, 4 of which required hysterectomy for significant bleeding, independent of gestational age, and the remaining 8 were treated with a variety of methotrexate, uterine artery embolization, and curettage with ligation of the descending branches of the uterine arteries.

However in our case series,. 3 out of 5 cases were managed with multidose methotrexate regimen, out of which 2 were exclusively managed, while the other 1 required higher modality of management, being suction and evacuation with Foley's tamponade/ ultrasound guided intra-cardiac $\mathrm{KCl}$ injection. The $5^{\text {th }}$ case required uterine artery embolisation. Hence a high degree of suspicion and an ectopic mind is needed to pick up such rare cases of cervical pregnancy. Cervical pregnancy has become not so rare now with risk factors like high caesarean rate and ART. Ultrasound remains the gold standard in diagnosis. Effective multimodality management reduces the risk of severe life threatening hemorrhage or hysterectomy.

\section{References}

1. Hansch E, Chitkara U, McAlpine J, El-Sayed Y, Dake MD, Razavi MK. Pelvic arterial embolization for control of obstetric hemorrhage: a five year experience. Am J Obstet Gynecol. 1999; 180:1454-1460.

2. Tang PP, Liu XY, Chen $\mathrm{N}$ et al. Diagnosis and treatment of cervical ectopic pregnancy. ([in Chinese) Zhonoggue Yi Xue Ke Xue Yuan Xue Bao. 2010; 32: 497-500.

3. Parente JT, Ou CS, Levy J, Legatt E. Cervical pregnancy analysis: a review and report of five cases. Obstet Gynecol. 1983; 62:79-82

4. Vela G, Tulandi T. Cervical pregnancy: the importance of early diagnosis and treatment. J Minim Invasive Gynecol. 2007; 14:481-484.

5. Ushakov FB, Elchalal U, Aceman PJ, Schenker JG. Cervical pregnancy: past and future. Obstet. Gynecol. Surv. 1997; 52(1):45-59.

6. Agdi M, Tulandi T. Surgical treatment of ectopic 
pregnancy. Best Pract. Res. Clin. Obstet. Gynaecol. 2009; 23(4):519-527.

7. Hung TH, Shau WY, Hsieh TT, Hsu JJ, Soong YK, Jeng CJ. Prognostic factors for an unsatisfactory primary methotrexate treatment of cervical pregnancy: a quantitative review. Hum. Reprod. 1998; 13(9):2636-2642.

8. Thomas RL, Gingold BR, Gallagher MW. Cervical pregnancy. A report of two cases. J. Reprod. Med. 1991; 36(6):459-462. 